\title{
"Fucking" geografia: entrevista com David Bell
}

\author{
Joseli Maria Silva \\ Universidade Estadual de Ponta Grossa (UEPG) - \\ Brazil \\ Paulo Jorge Vieira \\ Instituto de Geografia e Ordenamento do Território - \\ Universidade de Lisboa - Portugal
}

Há quinze anos o geógrafo britânico, David Bell, publicou um texto no periódico Environment and Planing D, Society \& Space sob o título de [Screw]ing Geography (censor's version). Este título foi resultado da censura editorial do título original Fucking Geography, de um trabalho anteriormente submetido ao encontro científico da Associação Americana de Geógrafos em 1994. Essa experiência pessoal/profissional de David Bell foi alvo de reflexão em outro texto, publicado em 2009, com o título Fucking Geography, Again. Neste último texto, o autor traz para discussão elementos que ultrapassam a escala pessoal de sua experiência, tornando visíveis as formas de poder que moldam o discurso geográfico e que produzem as pretensas verdades científicas.

Explorar a trajetória pessoal e científica desse impetuoso geógrafo é um excitante desafio para nós, geógrafos de lugares para além do mundo anglo-saxão e que estamos a construir nossas próprias lutas, em outros espaços-tempos para afirmar as sexualidades como elemento componente da análise geográfica.

David Bell realizou seu doutorado na Universidade de Birmingham em 1995 e atualmente é Professor Adjunto do Curso de Geografia na Universidade de Leeds, na área de Geografia Humana Crítica. Bell é também membro do Centro Interdisciplinar de Estudos de Gênero, desenvolvendo pesquisas nas áreas de geografia humana e cultural. David Bell, sob enfoque urbano e também rural, aborda o consumo, os estilos de vida, as tecnologias e as sexualidades em sua produção acadêmica.

A abertura do contexto acadêmico geográfico para os estudos sobre as sexualidades foi um árduo trabalho, do qual David Bell participou ativamente, tendo como importantes parceiros científicos Gill Valentine e Jon Binnie, entre outros. Com Valentine organizou em 1995 o volume "Mapping Desire - Geographies of Sexualities", que constitui a primeira obra coletiva sobre geografias das sexualidades. Com Binnie escreveu o seminal fulgurante volume "The Sexual Citizen - Queer Politics and Beyond" (2000). As repercussões de seu trabalho intelectual, certamente contribuíram para a proliferação de estudos sobre as sexualidades na geografia.

Os frutos resultantes de atitudes pioneiras e provocativas aos campos científicos estabelecidos são sempre, paradoxalmente, compostos de dores e delícias. É em torno da trajetória científica geográfica desse autor, mesclada com suas percepções pessoais, que gira esta entrevista .

Joseli Maria Silva e Paulo Jorge Vieira: Screwing Geography/fucking geography foi motivo de polêmicas em torno das formas de produção do conhecimento científico, bem como, das relações de poder que envolvem a validação de certas abordagens e linguagens no âmbito acadêmico. Qual é a sua avaliação sobre os frutos que colheu por publicar essas ideias?

David Bell: No início, a ideia de "fucking" geografia era, essencialmente, uma brincadeira e uma provocação. Eu queria ser um pouco ofensivo ou controverso, como uma forma de agitar as coisas. Mais especificamente, para sacudir a conferência anual da Associação de Geógrafos Americanos(AAG), onde o artigo era para ser apresentado. Eu esperava fazer alguma polémica. E, claro, a história ficou ainda melhor, ou pior, dependendo do seu ponto de vista, porque a comissão da AAG se recusou a deixar-me usar a palavra "fucking" no programa da conferência. Assim, após algumas cartas, para lá e para cá, o título do documento foi mudado, e que, por si só tornou-se um caminho para pensar sobre o que podemos e não podemos dizer em geografia. O título era um jogo de 
palavras, usando "fucking" tanto como verbo como adjetivo, sinalizando um desejo de foder (com) a geografia e, por outro lado, a exasperação com a disciplina. $\mathrm{O}$ trabalho todo foi originalmente inspirado por uma grande foto de Tom of Finland, que mostra um homem, literalmente, fodendo o globo. Eu usei essa imagem e uma de Della Grace, em minha palestra na AAG. Enfim, algumas pessoas disseram que gostaram do trabalho, que teve bastante atenção por causa do título. A sessão da conferência foi muito badalada, mas, no final, o texto é mais conhecido por uma palavra que está no título do que pelo resto do que eu estava tentando dizer. $\mathrm{O}$ trabalho em si, realmente foi apenas o início de um compromisso com a teoria queer e política, talvez parte do processo ambivalente de queerizar a geografia. Como eu disse, uma brincadeira é uma provocação. Então, tive o prazer de revisitá-lo em "Fucking Geography, Again" e ser capaz de reavaliar o incidente e as suas consequências, bem como, considerar o projeto mais amplo de "fucking" geografia. Mas, em termos de impacto sobre a disciplina é insignificante. Qualquer "choque" foi rapidamente absorvido. Fui convidado a publicar uma versão do artigo numa importante revista do tema, mas que também é marginal e foi apenas isso. Eu não acho que o texto realmente abriu um espaço para debater questões como a linguagem, ou o que é, ou não, apropriado falar num debate no contexto acadêmico. Ainda que esse debate estivesse a acontecer ao redor do texto de qualquer maneira. A Geografia mantém o melindre, como Bob McNee refere. Eu queria chamar a atenção para isso, brincar um pouco. Honestamente, muitos dos meus primeiros trabalhos tiveram esse caráter de brincadeira e provocação. A questão, portanto, permanece: "fucking" geografia? Não tenho a certeza que tenha sido.

\section{JMS e PJV: Seus estudos, de mestrado e doutorado, tiveram os proprietários fundiários como foco de interesse. Como a sexualidade passou a atrair sua atenção intelectual?}

DB: Bem, o início da minha carreira foi uma série de acidentes, eu nunca quis ser um acadêmico, mas acabei caindo nessa carreira. Eu tinha um emprego na área de ensino, em meio período em uma escola politécnica local, e foi oferecida à mim a oportunidade de estudar em um mestrado ao mesmo tempo. Eu comecei a trabalhar com a propriedade da terra, seguindo o conselho do meu ex-tutor, o grande geógrafo histórico Tony Phillips. Eu acho que ele realmente queria os meus resultados, mas não tinha tempo para sentar-se nos arquivos durante meses a fio, para a montagem dos padrões da propriedade da terra.
Foi um doutorado muito agradável e simples, com muitos mapas. Penso voltar ao tópico, na minha velhice! Eu, anteriormente, tinha estudado principalmente geografia física. Estava destinado a me tornar um cientista. Eu, na verdade, estava destinado a ser um geólogo, mas isso é outra história... Eu, certamente, nunca tinha pensado sobre a sexualidade como um tema de geografia e nunca me deparei como esse tema na graduação. Mas, então, comecei a ensinar geografia social e cultural, e geralmente, olhando em volta para áreas novas e interessantes de trabalho, folheando as revistas, li um texto de Larry Knopp (1990) na Geographical Magazine. Um texto que gerou uma série de respostas hostis, do tipo da mentalidade estreita, "que tem isso a ver com a geografia?". As respostas deixaram-me muito irritado, mas também vi que a sexualidade pode (e certamente deve) ser um tema de geografia. Assim, eu comecei a reunir o que havia sido publicado até então, o trabalho de Larry, Barbara Weightman, além de muitos trabalhos em outras disciplinas, sobre esses temas geográficos como a sociologia urbana, os estudos da mulher e claro, os trabalhos em Estudos Gays e Lésbicos. Coloquei "um punhado" de pedidos de empréstimo inter-bibliotecas, que também era parte da diversão. Talvez um legado do meu tempo nos arquivos quando estava no doutorado. Eu escrevi um artigo de revisão desses trabalhos, chamando os geógrafos a assumir seriamente a sexualidade como um tema. O texto "Insignificant Others" foi publicado na revista "Area" do Institute of British geographers, em 1991. Foi quando eu estabeleci contato com uma série de outras pessoas que trabalham na área, tais como: Gill Valentine, Jon Binnie e Julia Cream. Formamos, então, Sexuality \& Space Network, como forma de manter contato uns com os outros, sobre as nossas pesquisas e organizamos uma conferência de um dia em 1992, chamada "Lesbian and Gay Geographies", realizada na University College London - A conferência atraiu muitos interessados e apoiadores. Alguns dos oradores, mais tarde, contribuíram com textos para o livro Mapping Desire. Havia muito trabalho excitante a ser feito sobre a sexualidade, nesse momento. Principalmente fora da geografia, a teoria queer estava começando a ganhar destaque e também fez coro com a "virada cultural" na geografia humana. A sexualidade estava definitivamente na agenda. Então, pelo menos entre um pequeno grupo de geógrafos culturais, os interessados em temas como a identidade e em abordagens como o pós-estruturalismo.

J oseli Maria Silva e Paulo Jorge Vieira 


\section{JMS e PJV: Ao longo da sua carreira acadêmica foi professor no departamento de estudos culturais. Como vê a relação entre os estudos culturais e a geografia contemporânea?}

DB: Como eu já mencionei, há uma ideia, na história recente da geografia humana, pelo menos no Reino Unido, de uma "virada cultural", que ocorreu na década de 1980. Isso significou, na verdade, que muito geógrafos humanos começaram a ler obras de estudos culturais, que era uma área de grande crescimento na academia. Foi também, nessa época, que o pósmodernismo foi um tema quente e os dois se cruzaram de uma maneira interessante, ainda que às vezes, frustrante. Quando me mudei da geografia para os estudos culturais, em 1995, isso aconteceu parcialmente porque eu tinha uma formação geográfica e o meu novo chefe pensava que eu daria uma contribuição para os estudos culturais mais tradicionais, que eram essencialmente textuais. Estudos culturais foram se afastando do texto, das formas materiais, e ampliando um olhar mais para as práticas culturais e identidades culturais. Portanto, um geógrafo com trabalho sobre a sexualidade era, facilmente, transformado num professor de estudos culturais! É também verdade que algumas ideias de geografia foram vistas como um pouco "sexy", graças, principalmente, à " nova" geografia cultural (que foi, em grande parte, uma adaptação geográfica dos estudos culturais). Por isso, há algo, um pouco narcisista, no facto dos estudos culturais acharem a "nova" geografia cultural interessante). Eu acho que a geografia humana foi revificada e enriquecida com o seu encontro com os estudos culturais, embora muitas pessoas discordem e vejam a "virada cultural" como uma distração, ou um aborrecimento. Mas no meu ponto de vista, como já descrito em uma publicação para a Enciclopédia Internacional de Geografia Humana (Internation Encyclopedia of Human geography), a intersecção entre geografia/estudos culturais foi um encontro produtivo e empurrou a geografia para novas áreas interessantes. Hoje em dia, você ainda pode ver que o impacto nos tipos de trabalhos que estão sendo feitos em geografia humana. Infelizmente, os estudos culturais diminuíram como disciplina, pelo menos no Reino Unido. Foram vítimas da sua reputação (imprecisa) como uma espécie de crítica cultural populista (ou como aplicação da teoria de alta cultura na baixa cultura). Mas estou contente por me ter tornado um geógrafo, durante a "virada cultural", porque eu aprendi muito!

Os dez anos em que ensinei estudos culturais foi uma experiência realmente maravilhosa, que agora eu posso trazer de volta a minha prática pedagógica em
Geografia. Eu tive o privilégio de trabalhar ao lado de alguns colegas notáveis nos estudos culturais, principalmente no meu tempo na Universidade de Staffordshire, onde tive a liberdade para desenvolver o ensino e a pesquisa nas áreas que eu queria, que vão desde ciberculturas ao consumo, a política cultural.

JMS e PJV: Em 2000, juntamente com Jon Binnie, na obra "The Sexual Citizen" (Bell e Binnie, 2000), a questão da cidadania sexual e dos direitos sexuais adquirem uma espacialidade que muitas das investigações anteriores, de outras ciências sociais, haviam menosprezado. Que análise faz da importância que esta obra adquiriu no quadro da investigação queer? Como vê o debate atual sobre a cidadania sexual em nível global, onde aparentes formas de proteção identitária de direitos (conjugalidades e homoparentalidade) coexistem com críticas pós-identitárias crescentes?

DB: Para nós, parecia óbvio que a cidadania sexual tinha uma geografia, ou uma série de regiões, em diferentes escalas. Todos os aspectos da cidadania têm geografias, na verdade. Talvez essa seja apenas a maneira de pensar dos geógrafos - mas a forma como nos aproximamos da cidadania sexual teve um efeito positivo em inúmeros estudiosos na área. Esse livro é bastante apreciado por pessoas que trabalham com cidadania sexual e assuntos relacionados, por exemplo, aos estudos jurídicos queer. Eu acho, em grande parte, que foi devido à abordagem geográfica que, inevitavelmente, a obra tomou. É evidente que uma grande parte do debate sobre cidadania sexual tem se dado na escala global, a noção de uma "cidadania gay global", ou do que Lisa Duggan chamou de "a nova homonormatividade", que é uma espécie de modelo ocidental globalizado do "bom cidadão gay". Mas nós não queríamos ver isso de um modo tão simples. Como geógrafos, estávamos conscientes de que os fluxos globais, não produzem apenas homogeneidade. O modo como eles "aterrizam" e interagem em locais específicos, produz uma paisagem variada. O problema com a globalização desta "nova homonormatividade" é que ela é acompanhada de um script sobre como ser gay e isso é encarado com resistências e também aceitações. Ao mesmo tempo, a "tolerância" é tomada como um sinal de ser moderno e isso tem sido usado com eficácia, em alguns lugares, para defender direitos com base no desejo de ser visto como moderno (ou ocidental, ou europeu, ou qualquer outra coisa). Estes são realmente interessantes e importantes temas que são profundamente geográficos. 
Jon tem escrito muito mais sobre esta questão no seu livro "A Globalização da Sexualidade" (Binnie, 2004) e está explorando-o em um projeto que está atualmente trabalhando com seu colega Christian Klesse, olhando para o ativismo LGBT transnacional na Europa. Os recentes debates sobre o casamento gay na Argentina também têm seguido uma linha familiar em termos de pensar sobre o que diz sobre a legalização da nação. E, como temos visto, em outros lugares, trazendo o conflito para com a igreja. A religião transformou-se numa "falha geológica" importante nos avanços em torno da cidadania sexual, algo que não exploramos suficientemente em "The Sexual Citizen". Gill Valentine e alguns colegas da Universidade de Leeds recentemente terminaram um projeto sobre a Igreja Anglicana no Reino Unido, E.U. e África, que reforçou esse ponto. Nós não só temos que considerar o Estado apenas como a maior influência sobre a forma como a cidadania sexual se constitui, mas também outras influências poderosas como a religião.

$\mathrm{Eu}$ ainda acho, que debates sobre cidadania têm sido muito importantes no ativismo e nos estudos queer, embora tenham também sido objeto de crítica e desconstrução. $\mathrm{O}$ apelo às questões da cidadania é, todavia, muito poderoso, embora com restrições. Isto porque, apesar da cidadania ser normativa, nem todos se encaixa no perfil de um cidadão que surge. Pedindo para se tornar um cidadão, significa aceitar responsabilidades, bem como, ganhar direitos. É um negócio, e não é sempre equilibrado em seu favor. Este tem sido um dos grandes debates sobre o que os "queer" devem exigir e o que está em jogo quando se pede para ser um cidadão? Em The Trouble with Normal, Michael Warner (2000) coloca essas perguntas de forma interessante. Nós tentamos pensá-las através de "The Sexual Citizen" também. Em 2006, Jon e eu, editamos um volume especial da revista Politcal Geography, que revisitou as geografias da cidadania sexual e que incluía um texto de Michael Brown, que trouxe, precisamente, o tema das obrigações (em vez de direitos), que cidadania sexual traz (Brown, 2006).

Mas, agora, temos novos debates em que pensar, também, como nós, de alguma forma, nos movemos "além de" identidade e portanto, talvez também além de noções como direitos, cidadania e política identitária. Todas essas coisas foram criticadas, mas eles ainda são poderosamente atraentes.

JMS e PJV: Um dos elementos de novidade da sua
investigação é a abordagem das práticas sexuais
minoritárias, identificadas como fetichistas,
"dogging" (Bell, 2006) ou o sado-masoquismo
(Bell, 1995). Qual a potencialidade do estudo
destas práticas para a construção de um conhecimento na Geografia Humana? 0 campo, potencialmente conservador da geografia, está preparado para debater este tipo de investigação?

DB: Uma grande parte do meu interesse sempre foi nas culturas sexuais, sobre como os diferentes grupos desenvolvem maneiras de fazer sexo, formas de identificação (ou desidentificação). Eu acho que é parte da minha visão de mundo dos estudos culturais para ver formações culturais, como coisas muito interessantes para estudar. Eu sempre gostei daquela antropologia urbana e do trabalho simbólico interacionista dos E.U.A., de lugares como da Escola de Chicago, trabalhos sobre as casas de banho publicas, os espaços de descanso nas estradas e outros espaços de pegação. Eu gosto da atenção ao detalhe, para olhar de perto, como as diferentes culturas de trabalho sexual e quero vê-los como expressões criativas (para uma interessante discussão sobre o legado do trabalho, ver Irvine, 2003). Estou interessado na interação do lugar, dos corpos, desejos e fantasias. Em um nível, você pode desenvolver este tipo de investigação sobre estes temas na geografia, enquanto você mostrar que há algum tipo de dimensão espacial, que é um fenômeno geográfico. Mas, como eu já disse, há também muita delicadeza e não por isso, é sempre um caminho fácil. Dito isto, eu acho que é notável a gama de temas que são inscritos agora em geografia, da bestialidade a clubes de strip, do erotismo da biblioteca para a praia de nudismo. Acho que foi uma grande conquista do trabalho das geografias das sexualidades (é aqui necessário um plural), despertando o interesse nas diferentes formas em que os corpos, desejos, etc., podem se constituir. Em termos de questões mais amplas de produção de conhecimento, bem, faz parte de um diálogo permanente sobre o que constitui os temas legítimos para a investigação e legítimas formas de fazer pesquisa. Eu acho que algumas conquistas reais foram feitas nesse debate, como parte de uma reavaliação crítica do modo como fazemos geografia. Parece existir uma maior aceitação, embora ainda com limites, sobre o que pode ser a geografia.

Às vezes existem razões específicas para escrever sobre culturas sexuais. Por exemplo, meu trabalho sobre sadomasoquismo foi motivado, teórica e politicamente, como forma de responder a um processo judicial, aqui no Reino Unido, no qual um grupo de homens gays foram acusados de agressão (e várias outras coisas) por se envolver em práticas sexuais sadomasoquistas consensuais. Esse caso tornou-se muito conhecido entre os estudiosos queer no Reino Unido, porque lançou o debate sobre a 
construção legal da cidadania. O caso foi debatido na Câmara dos Lordes, onde foram ditas algumas coisas incrivelmente estranhas o que lhe permitiu ignorar a questão do consentimento, não importando que esses homens tivessem consentido, os atos reais foram ainda vistos como assalto. Eu também estava interessado na politização do sadomasoquismo, que ofereceu uma maneira diferente de pensar o político para além dos movimentos LGBT, precisamente porque se centrou em atos, em vez de identidades.

O texto de "dogging" veio de uma direção muito diferente. Foi, em parte, uma forma de ligar com o meu trabalho sobre tecnologias, que é uma área que eu venho desenvolvendo algum trabalho (a vida sexual e tecnologias). Mais recentemente, tenho escrito sobre as tecnologias de vigilância (Bell, 2009) e estou trabalhando, atualmente, em um capítulo chamado "new sexual affordances", que olha para esta questão, com base em trabalhos científicos e estudos de tecnologia, bem como, estudos de sexualidade. Eu estou interessado em como as tecnologias são incorporadas nos repertórios sexuais e aumentam ou, até mesmo, ajudam a construir novas culturas sexuais como o dogging que provavelmente não existiria sem o carro, o telemóvel e a internet.

JMS e PJV: Em seu trabalho "Queer country: rural lesbian and gay lives", publicado com Gill Valentine em 1995, há uma importante contribuição para desmantelar a tradicional abordagem de oposição e hierarquia entre os espaços rural e urbano na ciência geográfica. Qual foi o impacto deste trabalho em outras áreas da geografia para além dos grupos dos estudiosos das sexualidades?

DB: Bem, eu acho que a geografia rural/estudos rurais também foi afetada pela "virada cultural" e começou a trazer diferenças sobre o que significa o rural. Tem havido uma enorme quantidade de investigação que não apenas repensa o rural, bem como, a forma como o pensamos. Incluímos a sexualidade como um tema legítimo para pensar essa transformação. Quando Chris Philo escreveu sobre os "outros rurais negligenciados " (Philo, 1992), ele preparou, em parte, o caminho para um enfoque na sexualidade. Esta tem sido, creio eu, um das mais interessantes e acolhedoras áreas de investigação.

Em um nível mais amplo, eu acho que você pode ler as investigações da sexualidade na geografia rural como um símbolo de como a pesquisa sobre sexualidades penetrou em muitas áreas da geografia. E isso é também parte da missão que nos propusemos assim que nós fomos a eventos científicos da geografia política e da geografia rural, não apenas os eventos da geografia cultural. Queríamos trazer a sexualidade em tantas áreas diferentes, como já disse antes, mas o que eu ainda gostaria de conquistar é a geografia do transporte. Há tantos temas de interesse potencial, como pegação no carro, ou nas estações ferroviárias. Um dia, eu vou encontrar tempo para escrever um texto e enviá-lo para uma das revistas "mainstream" de geografia dos transportes. Estamos a assistir, também, que a divisão entre geografia humana / física está a ser quebrada, com edição do livro organizado por Cate Mortimer-Sandilands e Bruce Erikson (2010) Queer Ecologies. Esta é uma área muito excitante no momento.

\section{JMS e PJV: As relações entre as geografias feministas e queer envolvem aproximações e distanciamentos. Quais são os limites a serem reconhecidos e as afinidades produtivas entre estes dois campos de saber?}

DB: $\mathrm{Eu}$ começaria por dizer que algumas(uns) geógrafas(os) feministas têm sido extremamente solidárias(as) e têm contribuído muito para a agenda das geografias das sexualidades. $\mathrm{E}$ nós compartilhamos um espaço teórico também. A teoria feminista tem sido profundamente influente $\mathrm{e}$ importante. Os estudos de gênero como uma "disciplina" tem sido um dos locais onde o trabalho interessante interdisciplinar sobre a sexualidade está sendo realizado. É claro que existem diferenças e, às vezes, tensões. Nós não estamos centrados exatamente nas mesmas preocupações. Mas a frase que vocês usam, "afinidades produtiva", resume muito bem. Um par de anos atrás, organizamos uma conferência em Leeds para explorar as interseções das geografias feministas e queer, que oferecia uma oportunidade para reavaliar as afinidades produtivas. Revistas como Gender, Place and Culture têm sido muito receptivas às publicações de trabalhos sobre sexualidades.

Tenho, de facto, recentemente pensando sobre como a história da geografia e do envolvimento com a sexualidade é contado e explicado nas histórias da disciplina. Às vezes, a sexualidade fica como um subcampo do trabalho feminista. Eu não acho que é exatamente correto. Eu acho que o trabalho da sexualidade surgiu no cruzamento de várias especialidades e subdisciplinas. Mas é, certamente, verdade que o trabalho feminista foi uma inspiração e ajudou a apontar-nos para teorias úteis e métodos inovadores. O nosso livro "The Sexual Citizen", por exemplo, baseou-se muito nas investigações feministas. Foi em parte, também, as feministas, que nos lembraram (e nós igualmente a elas) para a 
importância de estudar a heterossexualidade.

\section{JMS e PJV: A incorporação da teoria queer na abordagem das sexualidades possibilitou avanços na análise geográfica. Quais são, em sua opinião, as principais contribuições teórico- metodológicas da chamada "Geografia Queer" para a ciência geográfica como um todo?}

DB: Eu duvido que tenha havido muitas contribuições para a ciência geográfica como um todo! A maior parte da geografia permanece resolutamente não afetada pelo "queer". Mas, nas áreas onde tem havido efeito, acho que é similar ao que aconteceu em outras disciplinas. Primeiro, é a abertura de novos temas e tópicos e, em certa medida, ter legitimado o estudo da sexualidade, das práticas sexuais e, assim por diante. $O$ queer também deixou de ser um substantivo, um objeto a ser estudado, para ser um verbo, algo feito para a disciplina. A Geografia tem sido queerizada? Sim e não. O coração da ciência geográfica tradicional continua a ser praticamente imune, apesar de algumas pessoas estarem tentando, por exemplo, o trabalho de Larry Knopp e Michael Brown (2003), sobre a teoria da difusão ou migração. Ou os trabalhos de J.K. Gibson-Graham (1996) na área da geografia económica e política. E, certamente, nas áreas mais afetadas pela "virada cultural". Como Jon escreveu em seu texto: "Cooming out of Geography" (Binnie, 1997), que é uma das contribuições mais importante para este debate, há uma necessidade de pensar queer como uma epistemologia e uma metodologia. Acho que mais progressos têm sido feitos ultimamente, em grande parte (como sempre na geografia), importando e "geografizando" debates tidos em outras disciplinas sobre metodologia "queer".

Epistemologicamente, a teoria queer é, muitas vezes, enquadrada no pós-estruturalismo e por isso, parece ter provocado alguma reflexão sobre o que é a geografia e o que significa fazer geografia. Mais amplamente, é claro, é através da "geografia queer" que os pensadores-chave, tais como Judith Butler têm sido popularizados (se é que é a palavra certa) na geografia. Nós temos sido parte de uma conversa animada. Com certeza, que teve um impacto, embora não um impacto universal, sobre toda a geografia. Como eu disse antes, uma das possibilidades mais interessantes, que está a começar a ser explorada é na geografia física, ou talvez querizando a divisão física/humana na geografia. Eu sinto que é uma área que precisa de continuar a insistir e onde há um grande trabalho a ser feito (mas não apenas por geógrafos). Ideias como a natureza "queer" parece-me ser bem interessante, vale a pena explorar.

\begin{abstract}
JMS e PJV: As relações entre a academia, os movimentos sociais e o Estado são elementos crescentes de discussão no âmbito científico. Como vê, a partir da sua experiência (Bell, 2007), a importância da construção de um conhecimento científico emancipatório como elemento de transformação das sociedades contemporâneas neste momento de crise? E qual o papel da Geografia?
\end{abstract}

DB: Eu tenho realmente me interessado em debates recentes sobre as chamadas "geografias públicas", que revigorou a discussão sobre a relevância da geografia e sobre o nosso impacto para além da academia. É evidente que há muitas dimensões diferentes para isso, a partir de abordagens muito estreita instrumentais (que procuram provar "impacto", a fim de marcar pontos nas avaliações de pesquisas ou para ganhar bolsas de investigação, por exemplo) ou pensar muito mais amplo sobre o conhecimento e seus usos.

Uma vertente desta divisão entre academia e ativismo diz respeito a encontrar formas de tornar o nosso trabalho politicamente útil. Eu não acho que devemos esperar que os ativistas (ou quem quiser) simplesmente peguem as nossas ideias e as coloque em prática. Acho que nós temos a responsabilidade de pensar em maneiras em que o nosso trabalho pode ser capaz de fazer a diferença. Eu porém, nem sempre, me sinto particularmente otimista sobre isso. Lembro-me de estar em uma conferência em que estava tentando construir uma ponte sobre essa divisão ativista/acadêmico, e Jeffrey Weeks estava falando sobre sua conceituação de identidade como uma "ficção necessária". Embora isto pareça bastante autoevidente e incontroverso para qualquer pósestruturalista, alguns dos auto-identificados ativistas na plateia ficaram indignados. Como ele ousava chamar suas identidades, em torno do qual eles estavam lutando, de ficções! Assim, enquanto poderíamos contar uma história da política queer e da teoria queer, trabalhando em harmonia, há sempre dificuldades de tradução e o perigo de apropriação. Veja como Butler tinha que tentar clarificar o seu trabalho da performatividade, tentar nos convencer de que ela não tinha a intenção de se inferir que todos os modos de parecer, ou todas as identidades, são drag (Butler, 1993).

Além das questões específicas de geografia queer, existem questões maiores aqui. No Reino Unido, temos estado a debater a pertinência da geografia por algum tempo, ou, como Noel Castree (2002) muito bem colocou, nós temos de nos preocupar com "o 
espectro da irrelevância ". O debate, geografias públicas, é o mais recente de uma a história mais longa. Não devemos ver isso como uma questão de direito, que deve ser escutado ou consultado, mas sim trabalhar onde e como queremos intervir. Eu acho que é saudável pensar o mundo exterior à universidade e que nós temos diversos "públicos" com os quais poderíamos (e deveríamos) interagir. No Reino Unido, no entanto, perdemos o papel do "intelectual público" e, no ensino superior, isto tem sido visto como pouco importante, ou importante apenas para a geração de riqueza. Precisamos resistir a isso, mas não por recuar em obscurantismo intelectual. Eu gosto do debate sobre o tema, como no ensaio de Michael Warner em Públics and Counterpublics (2002).

As minhas próprias experiências, relacionadas com o texto que você se refere na pergunta, foi um pouco diferente, e foi mais restrita e instrumental, orientado pelos imperativos do meu empregador. A questãochave foi que escrevi sobre tradução, como fazer com que nossas ideias úteis sejam utilizáveis para públicos diferentes. E eu ainda acho que é uma questão fundamental, que é porque fazer coisas como entrevistas também é útil. Então eu gostaria de terminar agradecendo a ambos por me dar esta oportunidade para explicar, de uma forma muito pessoal, alguns dos pensamentos do geógrafo "impetuoso", sobre a fucking geography (em todos os sentidos da frase).

\section{Referências}

BELL, David. Insignificant Others: lesbian and gay geographies. Area, v. 23, p. 323-329, 1991.

BELL, David. [Screw]ing Geography (censor's version). Environment and Planing D, Society \& Space. n. 13, p. $127-131,1995$.

BELL, David, VALENTINE, Gill. Mapping desire. Geographies of sexualities. London: Routledge, 1995.

BELL, David, VALENTINE, Gill. Queer country: rural lesbians and gay lives. Journal of Rural Studies. v. 11, n. 2, p. 113 - 122, 1995.

BELL, David, BINNIE, Jon. The Sexual Citizen: Queer Politics and Beyond. Cambridge: Polity Press, 2000.

BELL, David. Bodies, Technologies, Spaces: on 'dogging'. Sexualities, v. 9, n 4, p. 387-407, 2006

BELL, David. Fade to Grey: some reflections on policy and mundanity. Environment and Planning A, v. 39 , p. 541-554, 2007

BELL, David. Cultural Studies and Human Geography. In KITCHIN, Rob, THRIFT, Nigel. International Encyclopedia of Human Geography. Elsevier, 2009.

BELL, David. Fucking Geography, Again. In: BROWNE, Kath, LIM, Jason, BROWN, Gavin. Geographies of sexualities: theory, practices and politics. Surrey, England: Ashgate Publishing Limited, 2009, p. 81-88.

BELL, David. Surveillance is Sexy. Surveillance Studies, v. 6, p. 203-212, 2009.

BINNIE, Jon. Coming Out of Geography: towards a queer epistemology? Environment \& Planning D: society \& space, v. 15, p. 223-237, 1997.

BINNIE, Jon. The Globalization of Sexuality. London, England: Sage, 2004.

BROWN, Michael. Sexual citizenship, political obligation and disease ecology in gay Seattle. Political Geography, v. 25, p. 874-898, 2006.

BUTLER, Judith. Bodies that Matter: on the discursive limits of "sex". New York, USA: Routledge, 1993.

CASTREE, Noel. Border Geography. Area, v. 34, p. 103-112, 2002.

IRVINE, Janice. "The Sociologist as Voyeur": social theory and sexuality research, 1910-1978. Qualitative Sociology, v. 26, p. 429-456, 2003.

GIBSON-GRAHAM, J.K. Queer(y)ing Capitalist Organization. Organization, v. 3, p. 541-545, 1996.

KNOPP, Lawrence. Social Consequences of Homosexuality. Geographical Magazine, May, p. 245,1990 .

KNOPP, Larry, BROWN, Michael. Queer Diffusions. Environment \& Planning D: society and space, v. 21, p. 409-424, 2003.

MORTIMER-SANDILANDS, Catriona, ERIKSON, Bruce. Queer Ecologies: sex, nature, politics, desire. Indiana, USA: Indiana University Press, 2010. 
"Fucking" geografia: entrevista com David Bell

PHILO, Chris. Neglected Rural Geographies: a review. Journal of Rural Studies, v. 8, p. 193-207, 2002.

WARNER, Michael. The Trouble with Normal: sex, politics, and the ethics of queer life. New York, USA: Free Press, 2000.

WARNER, Michael. Publics and Counterpublics.

Cambridge MA, USA: MIT Press, 2002. 